Research Article

\title{
Dynamic Risk Analysis in Metro Construction Using Statistical Process Control
}

\author{
Yichen Wang $\mathbb{D}^{1}{ }^{1}$ Hong Zheng, ${ }^{1,2}$ and Xinyue $\mathrm{Lu}^{1}$ \\ ${ }^{1}$ Key Laboratory of Urban Security and Disaster Engineering of Ministry of Education, Beijing University of Technology, \\ Beijing 100124, China \\ ${ }^{2}$ State Key Laboratory of Geo-Mechanics and Geo-Technical Engineering, Institute of Rock and Soil Mechanics, \\ Chinese Academy of Sciences, Wuhan 430070, China \\ Correspondence should be addressed to Yichen Wang; bp19890327@163.com
}

Received 29 November 2019; Accepted 8 January 2020; Published 14 February 2020

Academic Editor: Changzhi Wu

Copyright (c) 2020 Yichen Wang et al. This is an open access article distributed under the Creative Commons Attribution License, which permits unrestricted use, distribution, and reproduction in any medium, provided the original work is properly cited.

\begin{abstract}
Metro construction is normally carried out in complex engineering geological environment, so it can generate various risk events. In the process of metro construction, a scientific risk dynamic analysis is indispensable to reduce and control risks. In order to analyze the risk in metro construction more scientifically and reasonably, in this study, a new risk dynamic analysis method for metro construction is proposed using statistical process control. The method can analyse the risk level according to the process's capacity index and identify the characteristics of risk variation according to the statistical control chart. The risk level and the characteristic of risks may vary with dynamical updating of monitoring data, so the conclusion of risk evaluation for a time interval can be drawn and corresponding safety measures can be ascertained. The method ushers statistical process control, so the random factors in risk evolution can be considered fully. Then, the method is applied to the risk analysis of shield construction under the Beijing-Tianjin intercity railway in Beijing Metro Line 8, a typical risk problem in the traffic construction. The variation of the risk level and the characteristic of risks can be evaluated reasonably because the dynamical randomness is considered. Moreover, whether risk control measures should be taken and what the effective measures are can be ascertained explicitly.
\end{abstract}

\section{Introduction}

Metro construction projects contain many potential risks normally. Risk analysis aims to ascertain risk level and corresponding engineering measures. Therefore, risk analysis is an indispensable method for reducing and controlling risk [1-3]. According to the guidelines or criteria on engineering risk, risk analysis should be executed based on the corresponding indexes of different phases $[4,5]$.

The monitoring data are important indexes of risk analysis during the construction phase. So, risk analysis based on monitoring data is normally executed in the process of metro construction [6-9]. In existing case studies, the risk analysis method consists of two key stages. First of all, the controlling threshold of monitoring data must be ascertained based on experience, experiment, and numerical simulation [6-13]. And then, the risk level can be evaluated based on the ratio of the maximum monitoring value to the threshold $[7,14,15]$. The ratio usually varies with metro construction, so the risk level evaluated may vary dynamically. This idea about risk dynamic analysis can be used reasonably, simply, and conveniently in actual metro projects. However, the idea focuses on the maximum monitoring data during construction, and the variation characteristics of monitoring data cannot be considered fully. Especially, the dynamic randomness of data cannot be taken into account.

To consider the dynamic randomness of monitoring data, this study utilizes the statistical process control (SPC) method to evaluate the risk level during metro construction. The SPC method was invented by Shewhart, an American applied statistician, in the 1920s. This method was initially used in American war industrial production during the Second World War. After the war, Japanese civil industry 
adopted this method widely. It led to the rapid recovery of the national productivity and economy. Since then, the SPC method was paid attention gradually and used widely by western industrial enterprises $[16,17]$. Some scholars made the improvements and applications for SPC. For example, He et al. [18], Zhang and Cheng [19], and Ramadan [20] improved different control charts based on different practical demands. He et al. [21, 22] proposed, respectively, the risk analysis method and the optimization model for quality control of the proces by combing the SPC method. After years of development, the SPC method has become a mature tool in modern industrial quality control.

In civil engineering, the SPC method was used in health monitoring of bridges $[23,24]$ and quality or cost control of construction materials $[25,26]$. However, SPC is seldom used in the risk analysis of metro construction. The SPC method considers dynamic randomness of process evolution reasonably; therefore, the use of SPC in the engineering risk analysis should be considered. In this study, a new risk dynamic analysis (RDA) method of metro construction based on SPC will be proposed. The method can be referred by risk monitoring and analysis of various geotechnical engineering.

\section{Statistical Process Control}

2.1. Principle of the SPC Method. SPC is an analysis and control method of process evolution based on statistical inference. For a process evolution, the variation of corresponding data could consist of two parts. The first one is the random wave caused by random factors, and the second one is the trend variation caused by systematical factors. SPC aims to identify the characteristics of the variation and analyze the process reasonably, based on the concepts as follows.

(1) If the variation of corresponding data is only effected by random factors, the data should obey normal distribution. The process is considered to be controlled stably. This is called Normality Assumption.

(2) If the data obey a normal distribution $N\left(\mu, \sigma^{2}\right)$, the probability that the data are in the interval $[\mu-3 \sigma$, $\mu+3 \sigma]$ is $99.73 \%$. This is called $3 \sigma$ Criterion.

(3) The probability that the data are not in the interval $[\mu-3 \sigma, \mu+3 \sigma]$ is $0.27 \%$. The probability is very small. Therefore, a process evolution is not considered to be controlled stably if some data are not in the interval $[\mu-3 \sigma, \mu+3 \sigma]$. This is called the principle of nonoccurrence for a small probability event.

These concepts are also called $3 \sigma$ Criterion of Quality Control.

2.2. Execution of the SPC Method. The SPC method is executed from two aspects as follows.

(1) One is called the statistical control chart (SCC) analysis. The SCC analysis aims to ascertain whether a process evolution is controlled stably. Control line is the key of SCC, and it is ascertained based on $3 \sigma$
Criterion of Quality Control. By comparing control line and the data of a process, whether a process evolution is controlled stably can be ascertained.

(2) The other is called the process capacity index (PCI) analysis. PCI analysis aims to ascertain whether a process accords with expected requirement. PCI can be calculated based on $3 \sigma$ Criterion of Quality Control also. PCI corresponds with the probability that a process accords with requirement. The larger the PCI is, the larger the probability is.

According to the two aspects, the SPC method ascertains, respectively, whether a process evolution is controlled stably and whether a process accords with requirement.

\section{Risk Dynamic Analysis Based on SPC}

3.1. The Idea for the Application of SPC. As the description in Section 1, the existing risk analysis for metro construction focuses on some special data, and the variation characteristics of data cannot be considered sufficiently. Moreover, the consideration for randomness is the key of risk analysis, but the existing risk analysis cannot consider the randomness fully. SPC analyses the process based on statistical inference, so it can improve these deficiencies from the aspects as follows.

(1) SPC can ascertain the probability that a process accords with requirement, and the probability is a reasonable index of the risk level analysis.

(2) SPC can ascertain the stability of process evolution based on the analysis for dynamic randomness, and it corresponds to the characteristics of dynamic risk variation.

(3) SPC analyses the process based on the dynamic update of data, and it corresponds to the characteristics and demands of metro construction.

3.2. The Idea of the RDA Method. RDA can be built by using the SPC method. According to the monitoring data of settlement, RDA evaluates risks based on the two aspects.

(1) Risk level analysis (RLA): the PCI of the data in a time interval can be calculated, so the corresponding failure probability can be calculated. According to the probability, the risk level of metro construction in the time interval can be obtained.

(2) Risk variation identification (RVI): the SCC of the data in a time interval can be built, so whether the data variation is affected by systematical factors can be ascertained. According to the conclusion, whether risk variation of metro construction is controlled stably in the time interval can be obtained.

Based on these two aspects, the reasonable engineering measures in the time interval can be ascertained.

3.3. The Procedure of the RDA Method. RDA is a dynamic analysis method for metro construction. It will repeat some 
analysis processes as updating monitoring data during metro construction. The general steps of RDA are shown as follows.

Part A: risk identification, the basics of RDA:

(1) According to the characteristics of metro engineering, the engineering structures undertaking risks and the characteristics of risks are ascertained.

(2) According to the engineering structures undertaking risks, the corresponding observation points of settlement monitoring are determined.

(3) According to all the characteristics of structures undertaking risks, codes, guidelines, engineering experiences, and research findings, every risk loss classification (RLC) and the corresponding control thresholds of settlement are ascertained.

Part B: risk dynamic estimation, the key of RDA:

(4) Using the settlement monitoring data in current time interval, the PCI and SCC can be calculated based on the procedure shown in Figure 1.

SCC consists of two-dimensional coordinates and three control lines, Upper control limit (UCL), Central line (CL), and Lower control limit (LCL). The horizontal coordinate shows time points, and the vertical coordinate shows the corresponding statistical quantity of process evolution. UCL and LCL are the boundaries of small probability; CL is the center of statistical quantity. They can be calculated based on the 3 sigma $(3 \sigma)$ criterion and the statistical inference. These are as follows.

$$
\left\{\begin{array}{l}
\mathrm{UCL}=\mu+3 \sigma, \\
\mathrm{CL}=\mu, \\
\mathrm{LCL}=\mu-3 \sigma,
\end{array}\right.
$$

where $\mu$ and $s$ are the mean and standard deviation of parameters corresponding with process evolution, respectively. The calculation methods of $\mu$ and $s$ are different for different SCC.

PCI can be calculated as follows.

$$
\left\{\begin{array}{l}
M=\frac{\mathrm{CV}_{\max }+\mathrm{CV}_{\text {min }}}{2}, \\
D=\mathrm{CV}_{\max }-\mathrm{CV}_{\min }, \\
k=2 \cdot \frac{|\mu-M|}{D}, \\
B=6 \cdot \sigma_{\mathrm{Se}} \\
C_{\mathrm{pk}}=(1-k) \cdot \frac{D}{B},
\end{array}\right.
$$

where $\mathrm{CV}_{\max }$ and $\mathrm{CV}_{\min }$ are the upper bound and the lower bound of the parameters of process evolution, respectively. The $k$ is called the deviation ratio of statistical distribution. The $\sigma_{\mathrm{Se}}$ is the statistical standard deviation of the parameters of process evolution. $\mathrm{C}_{\mathrm{pk}}$ is PCI of the whole process evolution. The PCI and SCC will vary dynamically with data updating.

(5) The probability distribution of the RLC can be calculated using PCI as follows.

$$
\text { Fpro }=\Phi\left[-3(1+k) \cdot C_{\mathrm{pk}}\right]+\Phi\left[-3(1-k) \cdot C_{\mathrm{pk}}\right] \text {. }
$$

(6) The characteristics of risk variation can be identified according to SCC.

The process is considered to be stable and controlled if all the statistical quantity of process evolution in the whole process are in the interval [LCL, UCL].

Part C: Risk dynamic analysis, the goal of RDA:

(7) RLA and RVI in the current time interval can be executed based on the PCI and the SCC. These steps are repeated based on the procedure shown in Figure 1.

(8) According to RLA and RVI, the corresponding measures for reducing risk can be ascertained.

\section{Case Study of a Metro Shield Tunnel}

In this study, an RDA method for metro construction is proposed using SPC. Yet, the practicability and advantages of this method must be tested and verified before it is applied. Here, an actual metro construction project completed is analyzed by using an RDA method, in order to test and verify this method.

4.1. Project Overview. A metro shield tunnel project is selected. This project is "Tianqiao-Yongdingmen Wai" tunnel interval of Beijing Metro Line 8. Shield construction excavated two parallel tunnels from north to south. The axes of tunnels are parallel with the Yongdingmen Wai road. As shown in Figure 2, the tunnels are across under the railway bridge of Beijing-Tianjin intercity railway in the interval (K34+734.321 K34+767.547) of right tunnel and the interval (K34+733.111 K34+766.197) of left tunnel. This is a typical environmental risk problem.

4.2. Risk Identification. Beijing-Tianjin intercity railway is a high-speed railway. The design speed of this railway is $350 \mathrm{~km} / \mathrm{h}$. The smoothness of railway track is highly demanded. The shield construction must cause some settlement. The settlement affects the bridge structure and smoothness of railway tracks, and so it can reduce safety and comfort of high-speed trains. So, the settlement caused by the shield construction must be monitored and controlled strictly.

In this project, therefore, the engineering structure undertaking risks is the railway bridge. The major risk is the effect to railway tracks caused by shield construction. Ten monitoring points for settlement were set in two sides of the 


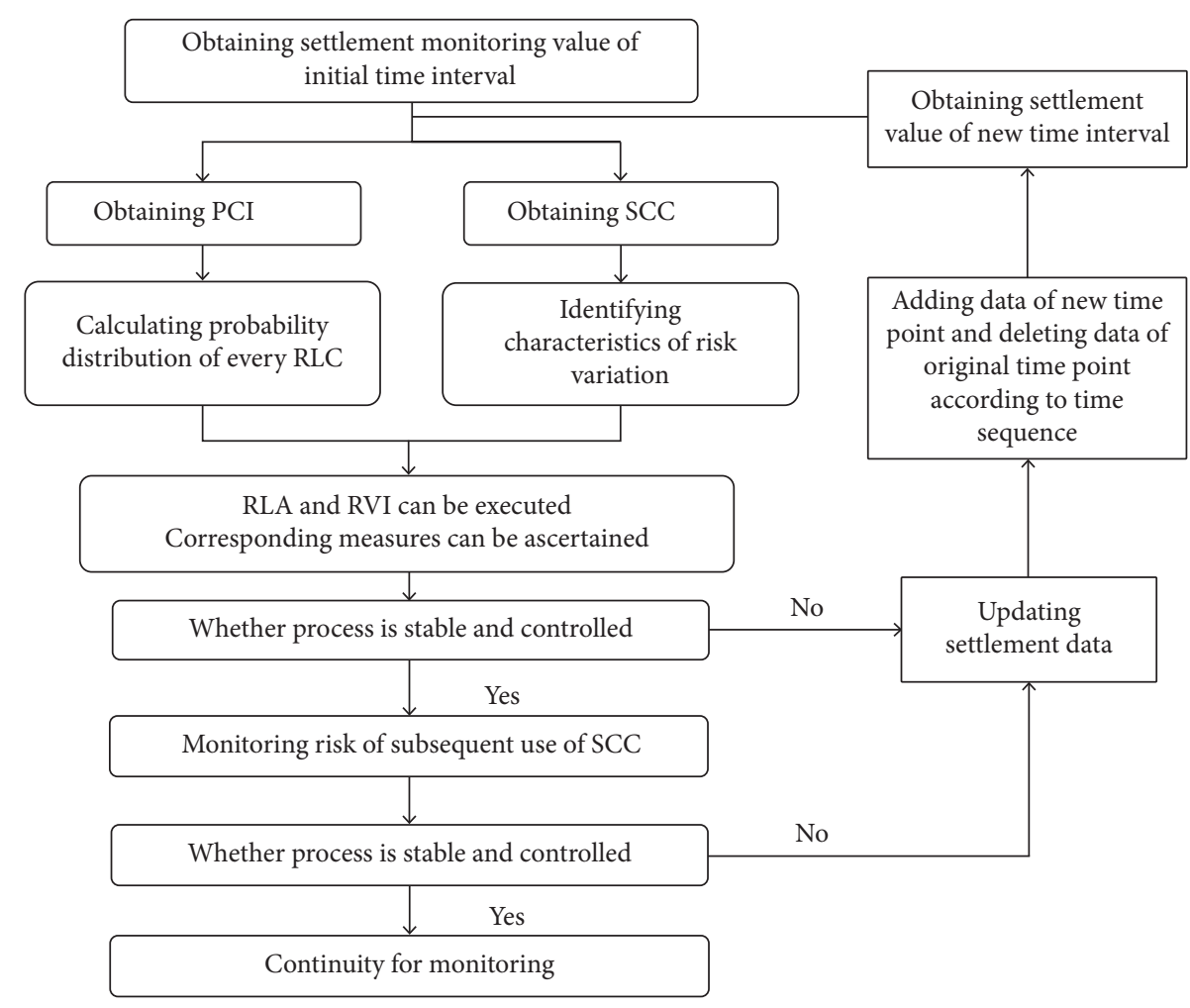

FIgURE 1: The procedure of RDA.

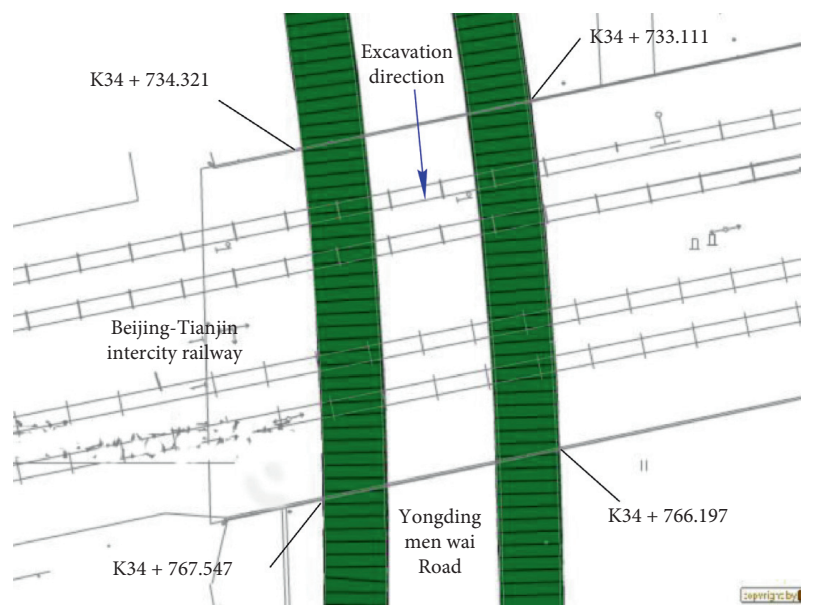

FIgURe 2: Plan of shield construction across under Beijing-Tianjin intercity railway.

railway, in order to monitor and control risks, as shown in Figure 3.

4.3. Normal Settlement Monitoring and Risk Analysis. During this shield construction, the interval of each tunnel is called the theoretical effect interval. When the shield excavation was in this interval, it is believed that the bridge is affected by the shield construction. In this project, the theoretical effect intervals are longer than the interval $(\mathrm{K} 34+734.321 \sim \mathrm{K} 34+767.547)$ of the right tunnel and the interval (K34+733.111 K34+766.197) of the left tunnel.

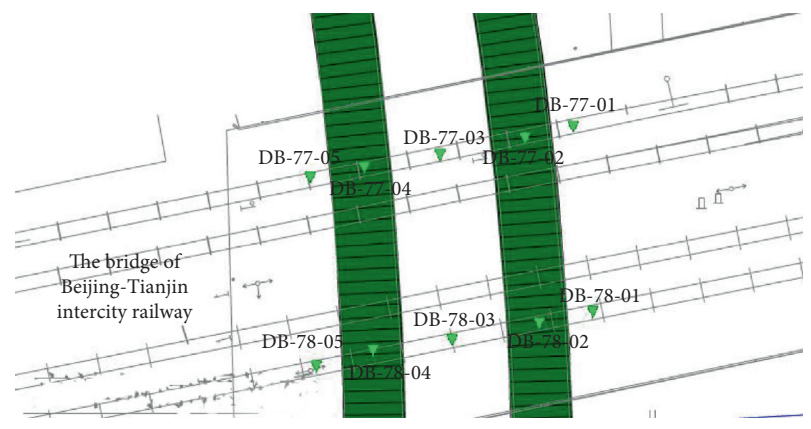

Figure 3: Deployment of observation points for settlement observation.

The procedure of settlement monitoring contains three time intervals: (1) 2017.04.14 2017.04.23, the excavation was approaching the theoretical effect interval, and five observation points in the north were working. (2) 2017.04.24 2017.05.04, the excavation was crossing the theoretical effect interval, and ten observation points were working. (3) 2017.05.05 2017.06. 15 , the excavation had passed through the theoretical effect interval, and ten observation points were working. The monitoring value of every time point shows final settlement of everyday, and there are 62 time points in total. These data show the process of settlement variation.

For the normal method, the risk level can be evaluated based on the ratio of the maximum monitoring value to the threshold $[7,8,15]$. In this engineering project, the risk evaluation report was compiled by the construction enterprise. The report presented some information as follows. The maximum monitoring values of each point are shown in 
TABLE 1: Maximum settlement values of observation points.

\begin{tabular}{|c|c|c|c|c|c|c|c|c|c|c|}
\hline $\begin{array}{l}\text { No. of observation } \\
\text { point }\end{array}$ & DB-77-01 & DB-77-02 & DB-77-03 & DB-77-04 & DB-77-05 & DB-78-01 & DB-78-02 & DB-78-03 & DB-78-04 & DB-78-05 \\
\hline $\begin{array}{l}\text { Maximum } \\
\text { settlement }(\mathrm{mm})\end{array}$ & -5.09 & -5.04 & -6.81 & -5.38 & -4.72 & -7.02 & -6.02 & -6.38 & -6.49 & -6.40 \\
\hline
\end{tabular}

TABLE 2: Risk loss classification and the corresponding settlement control range.

\begin{tabular}{lcc}
\hline & Risk loss classification & Control threshold \\
Grade & Description & $-2 \mathrm{~mm} \sim 2 \mathrm{~mm}$ \\
\hline Insignificant & Tiny settlement for roadbed,tiny effect for a moving train & $-5 \mathrm{~mm} \sim 5 \mathrm{~mm}$ \\
Considerable & More slight settlement for roadbed, decrease of comfort for a moving train & $-8 \mathrm{~mm} \sim 8 \mathrm{~mm}$ \\
Serious & Slight settlement for roadbed, less decrease of safety for a moving train & $-10 \mathrm{~mm} \sim 10 \mathrm{~mm}$ \\
Severe & Obvious settlement for roadbed, decrease of safety for a moving train & $-15 \mathrm{~mm} \sim 15 \mathrm{~mm}$ \\
Disastrous & More obvious settlement for roadbed, failure of safety for a moving train & \\
\hline
\end{tabular}

Table 1. According to $[27,28]$, the threshold of settlement is $-15 \mathrm{~mm} \sim 15 \mathrm{~mm}$. The ratios of the maximum monitoring value to the threshold are all less than 0.5 . As a result, the consequence of this environmental risk analysis is that the risk level is acceptable and the risk is controlled.

The normal method focuses on the maximum monitoring values particularly, so it does not consider fully the whole process of settlement evolution. The ratio of the maximum monitoring value to the threshold is defined as the index of risk level, so the uncertainty of risk cannot be considered fully.

4.4. The Risk Analysis of Initial Time Interval. In this section, the monitoring data of the initial time interval are obtained. RDA is carried out based on the RDA procedure. The initial time interval contains $1 \sim 10$ time points.

4.4.1. The Ascertainment of Risk Loss Classification (RLC). According to the risk identification in Section 4.2, $[5,27,28]$, RLC and the corresponding control threshold can be ascertained and presented as follows.

As shown in Table 2, when the settlement value exceeds the corresponding threshold, the failure situation is deemed to correspond with this RLC. For example, when the settlement value exceeds $-2 \mathrm{~mm} \sim 2 \mathrm{~mm}$, the RLC is deemed to be "Tiny settlement for roadbed, Tiny effect for a moving train.”

4.4.2. Identification of Characteristics of Risk Variation (RVI). RVI aims to ascertain whether risk variation is stable and controlled. The characteristics of risk variation can be ascertained by using the statistical control chart (SCC).

In this paper, SCC can be obtained by using X-R charts. An $\mathrm{X}-\mathrm{R}$ chart contains two charts, chart $\mathrm{X}$, and chart $\mathrm{R}$. Chart $\mathrm{R}$ is obtained firstly, and chart $\mathrm{X}$ can be obtained if chart $\mathrm{R}$ is stable and controlled.

Here is the procedure for obtaining chart R. In Figure 4, the range of settlement values in every time point and three control lines are shown. The coordinates of UCL, CL, and LCL are calculated as follows:

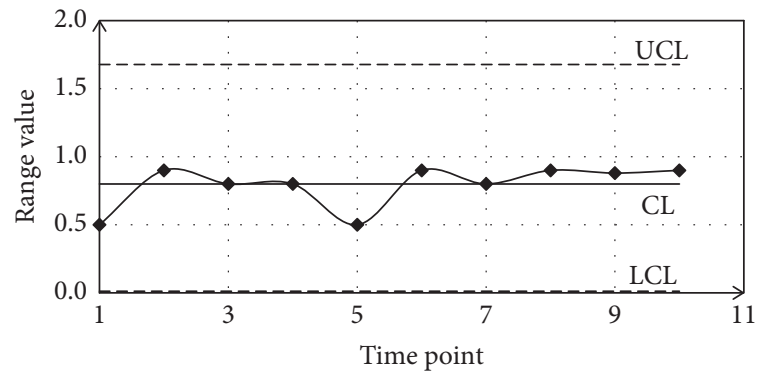

FIgURE 4: R control chart of initial time interval.

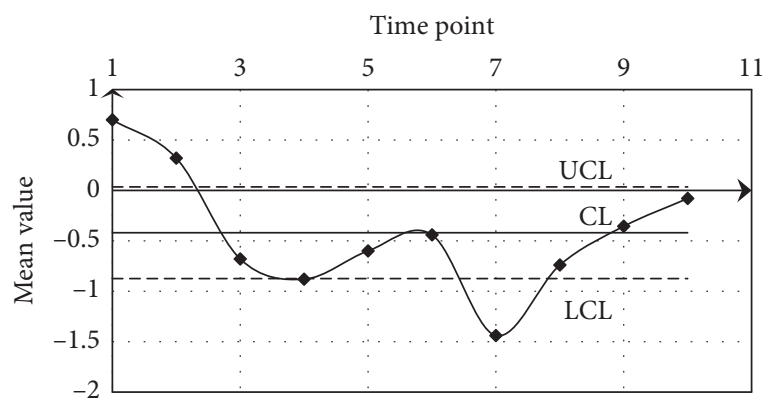

FIGURE 5: $\bar{X}$ control chart of initial time interval.

$$
\left\{\begin{array}{l}
\mathrm{UCL}_{\mathrm{R}}=D_{4} \cdot \operatorname{AveRe}(\mathrm{Se})=1.666 \\
\mathrm{CL}_{\mathrm{R}}=\operatorname{AveRe}(\mathrm{Se})=0.788 \\
\mathrm{LCL}_{\mathrm{R}}=D_{3} \cdot \operatorname{AveRe}(\mathrm{Se})=0
\end{array}\right.
$$

where $D_{3}=0$ and $D_{4}=2.114$ are statistical parameters dependent on the number of observation points. AveRe $(\mathrm{Se})=$ 0.788 is the mean of ranges in every time point.

Based on the principle of the SPC method, the process is considered to be stable and controlled if all the ranges in whole process are in the interval $\left[\mathrm{LCL}_{\mathrm{R}}, \mathrm{UCL}_{\mathrm{R}}\right]$. Chart $\mathrm{R}$ in Figure 4 is stable and controlled based on this principle.

Here is the procedure for obtaining chart X. In Figure 5, the mean of settlement values in every time point and three control lines are shown. The coordinates of UCL, CL, and LCL are calculated as follows: 
TABLE 3: PCI and corresponding FP of different control ranges.

\begin{tabular}{lccccc}
\hline Control range & $-2 \mathrm{~mm} \sim 2 \mathrm{~mm}$ & $-5 \mathrm{~mm} \sim 5 \mathrm{~mm}$ & $-8 \mathrm{~mm} \sim 8 \mathrm{~mm}$ & $-10 \mathrm{~mm} \sim 10 \mathrm{~mm}$ & $-15 \mathrm{~mm} \sim 15 \mathrm{~mm}$ \\
\hline PCI & 0.795 & 2.304 & 3.814 & 4.820 & 0 \\
FP & $0.87 \%$ & 0 & 0 & 0 & 0 \\
\hline
\end{tabular}

TABLe 4: Consequences of RLA.

\begin{tabular}{lccc}
\hline Risk loss classification & Probability & Frequency & Risk level \\
\hline $\begin{array}{l}\text { Tiny settlement for roadbed, } \\
\text { Tiny effect for a moving train }\end{array}$ & $0.87 \%$ & Unlikely \\
$\begin{array}{l}\text { More slight settlement for roadbed } \\
\begin{array}{l}\text { Decrease of comfort for a moving train } \\
\text { Slight settlement for roadbed }\end{array}\end{array}$ & 0 & Unlikely \\
$\begin{array}{l}\text { Less decrease of safety for a moving train } \\
\begin{array}{l}\text { Obvious settlement for roadbed } \\
\text { Decrease of safety for a moving train }\end{array}\end{array}$ & 0 & Unlikely \\
$\begin{array}{l}\text { More obvious settlement for roadbed } \\
\text { Failure of safety for a moving train }\end{array}$ & 0 & Unlikely \\
\hline
\end{tabular}

Report of risk dynamic analysis

1. Basic information

Time interval: 2017.04.14 2017.04.23

Monitoring index: settlement of railway roadbed in everyday

Observation point: DB-77-01, DB-77-02, DB-77-03, DB-77-04, DB-77-05

2. Statistical control chart

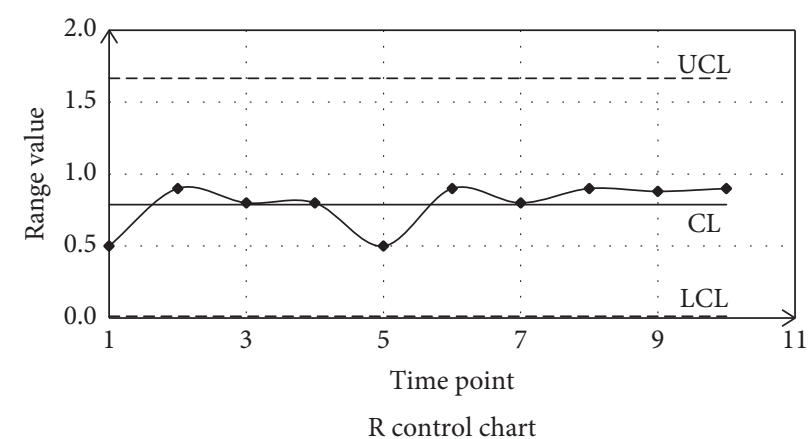

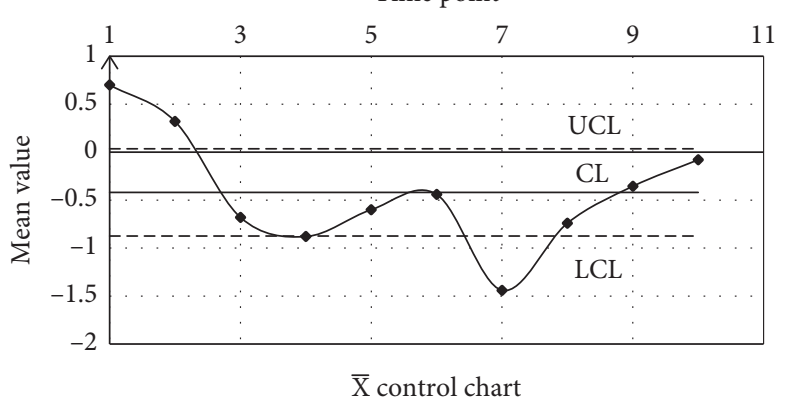

3. Table of RLA consequences

\begin{tabular}{|c|c|c|c|}
\hline Risk loss classification & Probability & Frequency & Risk level \\
\hline $\begin{array}{l}\text { Tiny settlement for roadbed } \\
\text { Tiny effect for a moving train }\end{array}$ & $0.87 \%$ & Occasional & IV \\
\hline $\begin{array}{l}\text { More slight settlement for roadbed } \\
\text { Decrease of comfort for a moving train }\end{array}$ & 0 & Unlikely & IV \\
\hline $\begin{array}{l}\text { Slight settlement for roadbed } \\
\text { Less decrease of safety for a moving train }\end{array}$ & 0 & Unlikely & IV \\
\hline $\begin{array}{l}\text { Obvious settlement for roadbed } \\
\text { Decrease of safety for a moving train }\end{array}$ & 0 & Unlikely & III \\
\hline $\begin{array}{l}\text { More obvious settlement for roadbed } \\
\text { Failure of safety for a moving train }\end{array}$ & 0 & Unlikely & III \\
\hline
\end{tabular}

\section{Risk evaluation conclusion}

In this time interval, risk level is IV and negligible. However, settlement variation is effected by systematical factors and risk is unstable and uncontrolled. Characteristics of settlement variation is reciprocating increase and decrease. Therefore, monitoring frequency should be increased and safe patrol should be strengthened, and the disadvantage affected by systematical factors should be avoided.

FIGURE 6: Report of risk dynamic analysis in initial time interval. 
Report of risk dynamic analysis

1. Basic information

Time interval: 2017.04.24 2017.05.03

Monitoring index: settlement of railway roadbed everyday

Observation point: DB-77-01, DB-77-02, DB-77-03, DB-77-04, DB-77-05

2. Statistical control chart
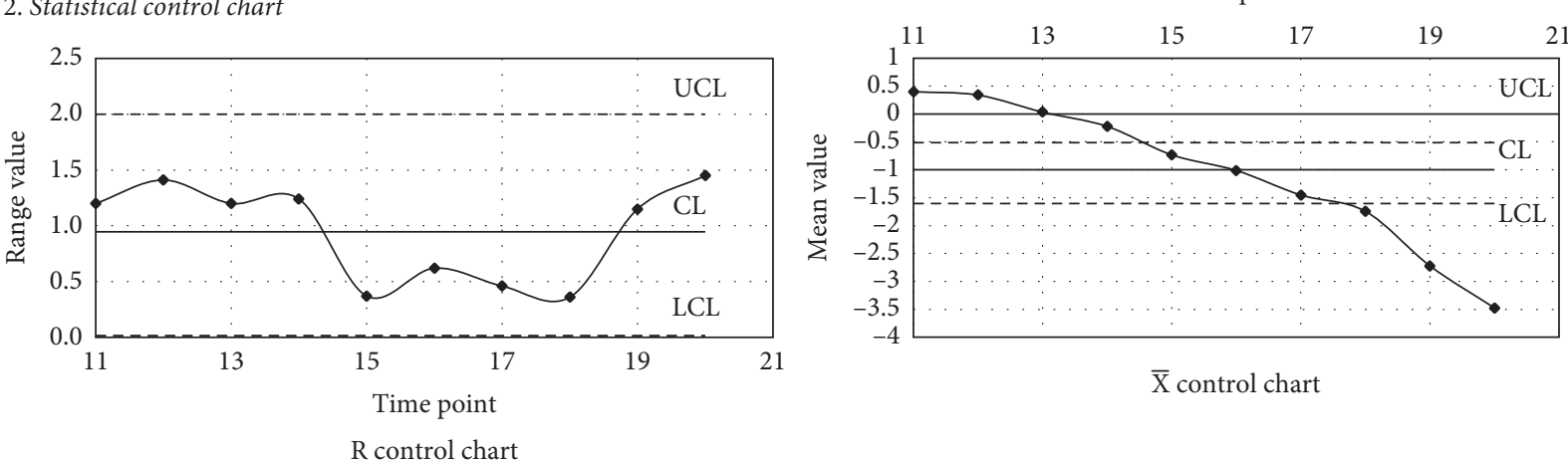

3. Table of RLA consequences

\begin{tabular}{|c|c|c|c|}
\hline Risk loss classification & Probability & Frequency & Risk level \\
\hline $\begin{array}{l}\text { Tiny settlement for roadbed } \\
\text { Tiny effect for a moving train }\end{array}$ & $14.88 \%$ & Frequent & III \\
\hline $\begin{array}{l}\text { More slight settlement for roadbed } \\
\text { Decrease of comfort for a moving train }\end{array}$ & $0.12 \%$ & Occasional & III \\
\hline $\begin{array}{l}\text { Slight settlement for roadbed } \\
\text { Less decrease of safety for a moving train }\end{array}$ & 0 & Unlikely & IV \\
\hline $\begin{array}{l}\text { Obvious settlement for roadbed } \\
\text { Decrease of safety for a moving train }\end{array}$ & 0 & Unlikely & III \\
\hline $\begin{array}{l}\text { More obvious settlement for roadbed } \\
\text { Failure of safety for a moving train }\end{array}$ & 0 & Unlikely & III \\
\hline
\end{tabular}

4. Risk evaluation conclusion

In this time interval, risk level is III and acceptable. However, settlement variation is affected by systematical factors and risk is unstable and uncontrolled. In the whole time interval, downward settlement value increase monotonically obviously. Therefore, monitoring frequency should be increased and safe patrol should be strengthened, and some settlement control measures must be strictly.

Figure 7: Report of risk dynamic analysis in time interval of the 10th update.

$$
\left\{\begin{array}{l}
\mathrm{UCL}_{\overline{\mathrm{X}}}=\operatorname{Ave}(\mathrm{Se})+\mathrm{A}_{2} \cdot \operatorname{AveRe}(\mathrm{Se})=0.035, \\
\mathrm{CL}_{\overline{\mathrm{X}}}=\operatorname{Ave}(\mathrm{Se})=-0.420, \\
\mathrm{LCL}_{\overline{\mathrm{X}}}=\operatorname{Ave}(\mathrm{Se})-\mathrm{A}_{2} \cdot \operatorname{AveRe}(\mathrm{Se})=-0.874,
\end{array}\right.
$$

where $A_{2}=0.577$ is statistical parameters dependent on the number of observation points. Ave $(\mathrm{Se})=-0.420$ is the mean of means in every time point.

Similarly, a process is considered to be stable and controlled if all the means in the whole process are in the interval [ $\mathrm{LCL}_{\mathrm{X}}$, $\mathrm{UCL}_{\mathrm{X}}$ ]. Chart $\mathrm{X}$ in Figure 5 is unstable and uncontrolled.

RVI has been completed based on the SCC analysis. It is ascertained that the variation of risks is unstable and uncontrolled in the initial time interval.

4.4.3. The Analysis of the Risk Level (RLA). RLA aims to ascertain the risk level. The failure probability (FP) of the settlement value exceeding the control threshold can be calculated based on PCI. According to the FP, the risk level can be ascertained.

For example, if the settlement control range is $-2 \mathrm{~mm} \sim 2 \mathrm{~mm}$, PCI can be calculated based on (2) as follows:

$$
\left\{\begin{array}{l}
M=\frac{\mathrm{CV}_{\text {max }}+\mathrm{CV}_{\text {min }}}{2}=0, \\
D=\mathrm{CV}_{\max }-\mathrm{CV}_{\text {min }}=4, \\
k=2 \cdot \frac{|\operatorname{Ave}(\mathrm{Se})-M|}{D}=0.210, \\
B=6 \cdot \sigma_{\mathrm{Se}}=3.975, \\
C_{\mathrm{pk}}=(1-k) \cdot \frac{D}{B}=0.795 .
\end{array}\right.
$$




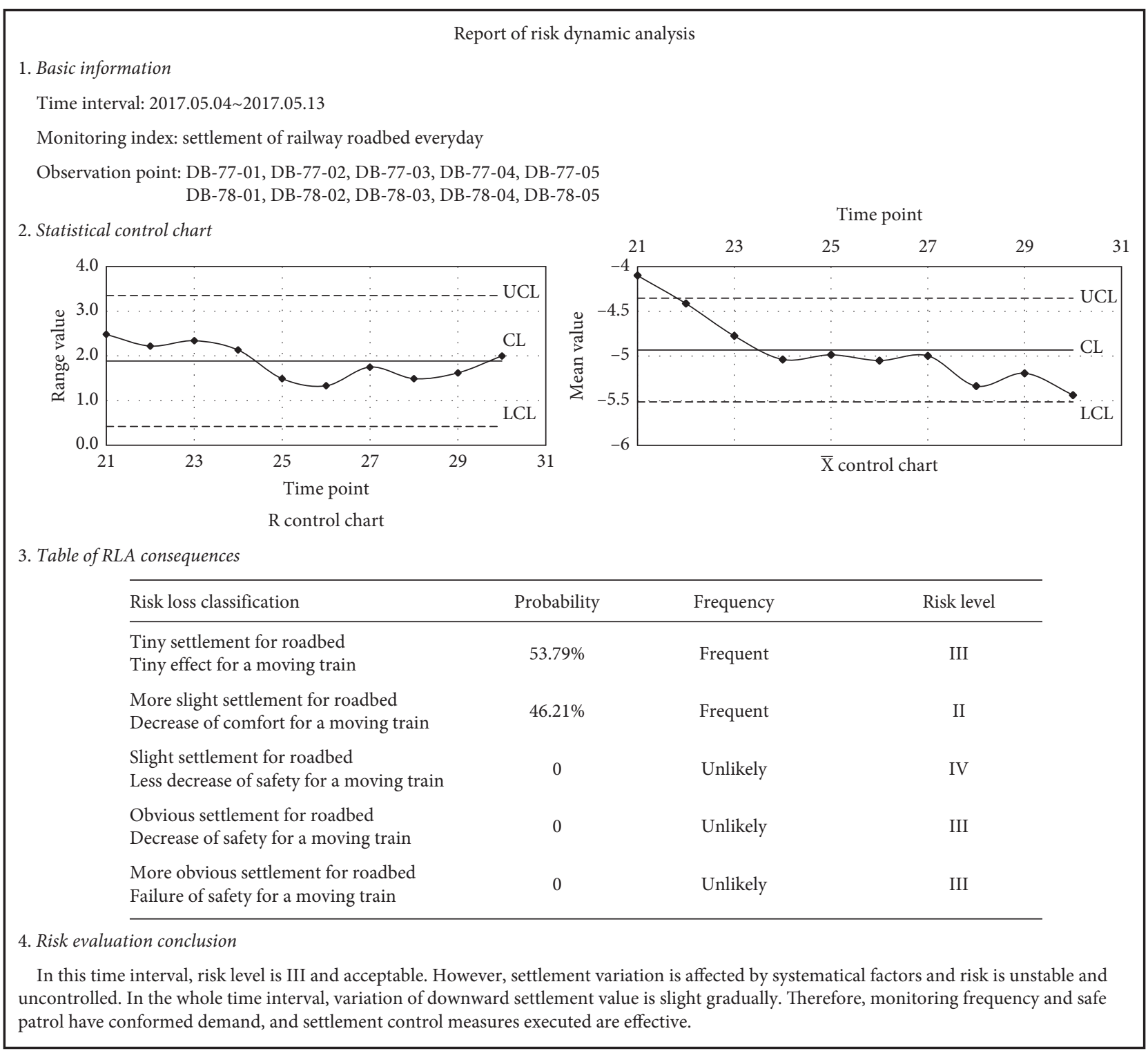

FIgURe 8: Report of risk dynamic analysis in time interval of the 20th update.

The failure probability that settlement exceeds control threshold can be calculated based on (3) as follows:

$$
\text { Fpro }=\Phi\left[-3(1+\mathrm{k}) \cdot \mathrm{C}_{\mathrm{pk}}\right]+\Phi\left[-3(1-\mathrm{k}) \cdot \mathrm{C}_{\mathrm{pk}}\right]=0.87 \% \text {. }
$$

According to the same procedure, PCI of the different settlement control ranges and the corresponding FP can be calculated. Consequences are listed in Table 3.

According to the consequences, the probability distribution of every RLC can be calculated. So, the risk level can be analyzed based on the probability distribution, Classification of Frequency and Consequence as well as [5]. The consequences of RLA are listed in Table 4.

4.4.4. The Risk Evaluation of Initial Time Interval. According to the abovementioned analyses, the report of risk dynamic analysis in the time interval can be obtained, as shown in Figure 6. It contains basic information, two charts, table of RLA consequences, and risk evaluation conclusion.

4.5. Risk Analysis of Subsequent Time Interval. In this section, the monitoring data of the subsequent time interval are obtained and RDA is carried out. According to the procedure, the new risk dynamic analysis should be conducted based on the update of data. RLA, RVI, and the corresponding report must be updated immediately if the data have a new update, by using the procedure in Section 4.4. In this paper, the reports in some new time interval are presented as follows, in order to test and verify practicability of RDA.

4.5.1. RDA in the Time Interval of the 10th Update. A report of RDA in this time interval can be obtained as shown in Figure 7. 


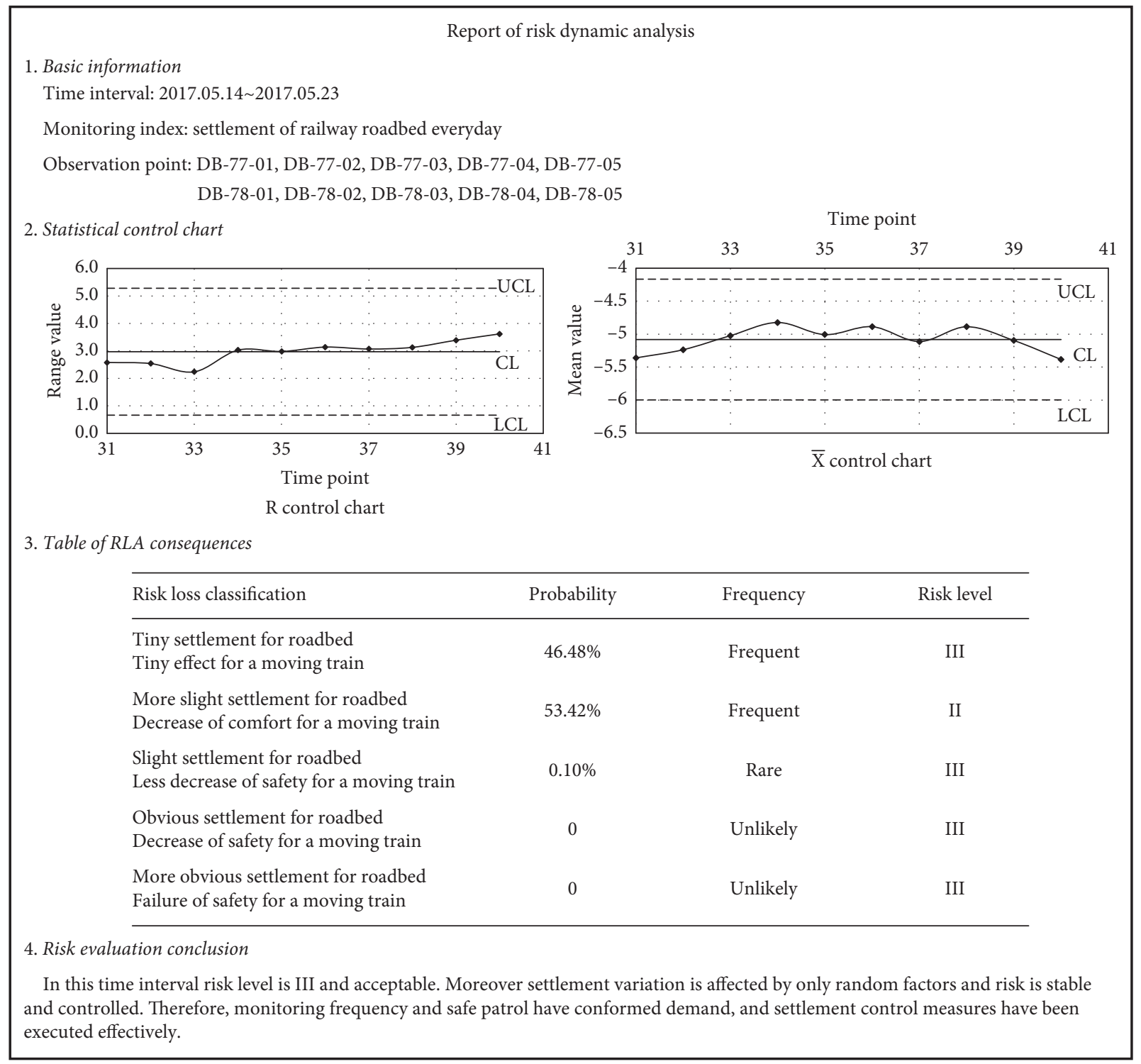

Figure 9: Report of risk dynamic analysis in time interval of the 30th update.

As shown in Figure 7, in this time interval, the shield excavation was crossing gradually the theoretical effect interval. The risk level and the characteristics of risk variation can be ascertained. The risk was increasing obviously. The reasonable engineering measures can be ascertained explicitly. During the actual construction, many control measures were taken strictly in this time interval, so the conclusion corresponds with actual engineering.

4.5.2. RDA in the Time Interval of the 20th Update. A report of RDA in this time interval can be obtained as shown in Figure 8.

As shown in Figure 8, in this time interval, the shield excavation was escaping gradually the theoretical effect interval. The risk level and the characteristics of risk variation can be ascertained. The risk was increasing slightly and trended stably. During the actual construction, many control measures were about to be completed in this time interval. The conclusion corresponds with actual engineering, but also it can indicate the effectiveness of the engineering measures executed.

4.5.3. RDA in the Time Interval of the 30th Update. A report of RDA in this time interval can be obtained as shown in Figure 9.

As shown in Figure 9, in this time interval, the shield excavation had escaped from the theoretical effect interval. The risk level and the characteristics of risk variation can be ascertained. The risk was stable and controlled completely. During the actual construction, many control measures were completed in this time interval, so the conclusion can indicate the effectiveness of the engineering measures executed again. 


\section{Conclusions}

In this paper, a new RDA method for metro construction has been proposed by using SPC. This method can evaluate the risk level by PCI and identify the characteristics of risk variation by SCC. Risk evaluation can be executed based on these two aspects. Due to the combination of statistical inference, this method can consider the dynamic randomness of whole risk evolution. The advantages of this method are as follows:

(1) The method can evaluate the risk level based on PCI, by calculating the probability distribution of risk loss classification. It combines the classification of frequency and consequence in current codes and guidelines about risk management. It corresponds with the concept of risk.

(2) The method identifies risk variation based on SCC, so risk control measures can be executed reasonably and scientifically. In the case study, unstable and uncontrolled risk variation can be identified explicitly, so risk control measures to be taken can be ascertained. Moreover, stable and controlled risk variation can be identified explicitly when risk control measures had been taken, so the effectiveness of risk control measures can be verified.

(3) This method carries out dynamic risk evaluation based on the dynamic update of settlement monitoring data. In the case study, the risk level and characteristics of risk variation may vary dynamically with data update during metro construction.

However, the study of this paper is preliminary. The following effort aims to apply the method to more engineering construction projects. We believe that the practicability and rationality of this method will be improved as practical applications are accumulated.

\section{Data Availability}

The data used to support the findings of this study are available from the corresponding author upon request.

\section{Conflicts of Interest}

The authors declare that there are no conflicts of interest regarding the publication of this study.

\section{Acknowledgments}

The study presented in this article was supported by the National Natural Science Foundation of China, Research Grant no. 51538001.

\section{References}

[1] L. Zhang, M. J. Skibniewski, X. Wu, Y. Chen, and Q. Deng, "A probabilistic approach for safety risk analysis in metro construction," Safety Science, vol. 63, pp. 8-17, 2014.

[2] Y. Q. Hao, X. L. Rong, L. J. Ma, P. X. Fan, and H. Lu, "Uncertainty analysis on risk assessment of water inrush in karst tunnels," Mathematical Problems in Engineering, vol. 2016, Article ID 2947628, 11 pages, 2016.

[3] Z. H. Luo, L. Zeng, H. Z. Pan, Q. J. Hu, B. Liang, and J. Q. Han, "Research on construction safety risk assessment of new subway station close-attached under crossing the existing operating station," Mathematical Problems in Engineering, vol. 2019, Article ID 3215219, 20 pages, 2019.

[4] S. D. Eskesen, P. Tengborg, J. Kampmann, and T. H. Veicherts, "Guidelines for tunnelling risk management: international tunnelling association, working group no.2," Tunnelling and Underground Space Technology, vol. 19, pp. 217-237, 2004.

[5] MOHURD China, Code for Risk Management of Underground Works in Urban Rail Transit, Standard of the People's Republic of China," GB 50652-2011, MOHURD China, Beijing, China, 2012, in Chinese.

[6] H. Huang, H. Shao, D. Zhang, and F. Wang, "Deformational responses of operated shield tunnel to extreme surcharge: a case study," Structure and Infrastructure Engineering, vol. 13, no. 3, pp. 345-360, 2017.

[7] Q. Fang, D. Zhang, and L. N. Y. Wong, "Environmental risk management for a cross interchange subway station construction in China," Tunnelling and Underground Space Technology, vol. 26, no. 6, pp. 750-763, 2011.

[8] Y. P. Guan, W. Zhao, S. G. Li, and G. B. Zhang, "Key techniques and risk management for the application of the pile-beam-arch (pba) excavation method: a case study of the Zhongjie subway station," The Scientific World Journal, vol. 2014, Article ID 275362, 16 pages, 2014.

[9] A. Sirivachiraporn and N. Phienwej, "Ground movements in EPB shield tunneling of Bangkok subway project and impacts on adjacent buildings," Tunnelling and Underground Space Technology, vol. 30, pp. 10-24, 2012.

[10] X. Li and D. J. Yuan, "Development of the safety control framework for shield tunneling in close proximity to the operational subway tunnels: case studies in mainland China," SpringerPlus, vol. 5, p. 527, 2016.

[11] J. Su, Q. Fang, D. L. Zhang, X. K. Niu, X. Liu, and Y. M. Jie, "Bridge responses induced by adjacent subway station construction using shallow tunneling method," Advances in Civil Engineering, vol. 2018, Article ID 8918749, 16 pages, 2018.

[12] M. Sharghi, H. Chakeri, and Y. Ozcelik, "Investigation into the effects of two component grout properties on surface settlements," Tunnelling and Underground Space Technology, vol. 63, pp. 205-216, 2017.

[13] J. Su, D. L. Zhang, Z. Y. Zhou, X. K. Niu, and Q. M. Tai, “Safety assessment and control of existing bridge crossed by tunnel construction," Chinese Journal of Rock Mechanics and Engineering, vol. 34, pp. 3188-3195, 2015, in Chinese.

[14] X. W. Ye, L. Ran, T. H. Yi, and X. B. Dong, "Intelligent risk assessment for dewatering of metro- tunnel deep excavations," Mathematical Problems in Engineering, vol. 2012, Article ID 618979, 13 pages, 2012.

[15] J. A. Clarke and D. F. Laefer, "Evaluation of risk assessment procedures for buildings adjacent to tunnelling works," Tunnelling and Underground Space Technology, vol. 40, pp. 333-342, 2014.

[16] R. Miao, Z. H. Jiang, and L. R. Cui, Engineering Statistics, China Machine Press, Beijing, China, 2010, in Chinese.

[17] J. D. Jiang and Y. C. Feng, Statistical Process Control, China Zhijian Publishing House, Beijing, China, 2011, in Chinese.

[18] Y. H. He, L. B. Wang, Z. Z. He, and Y. Wei, "Product reliability oriented design scheme of control chart based on the convergent CEV for censored characteristics," Mathematical 
Problems in Engineering, vol. 2015, Article ID 128491, 11 pages, 2015.

[19] M. Zhang and W. M. Cheng, "Recognition of mixture control chart pattern using multiclass support vector machine and genetic algorithm based on statistical and shape features," Mathematical Problems in Engineering, vol. 2015, Article ID 382395, 10 pages, 2015.

[20] S. Z. Ramadan, "Joint $\bar{X}$ and $S^{2}$ Control Charts Optimal Design Using Genetic Algorithm," Mathematical Problems in Engineering, vol. 2018, Article ID 6516879, 10 pages, 2018.

[21] Y. He, J. Cui, F. Liu, P. Duan, and D. Li, "Risk-oriented assembly quality analysing approach considering product reliability degradation," International Journal of Production Research, vol. 57, no. 1, pp. 271-284, 2019.

[22] Y. He, F. Liu, J. Cui et al., "Reliability-oriented design of integrated model of preventive maintenance and quality control policy with time-between-events control chart," Computers \& Industrial Engineering, vol. 129, pp. 228-238, 2019.

[23] T. H. Yi, H. N. Li, G. B. Song, and Q. Guo, "Detection of shifts in GPS measurements for a long- span bridge using CUSUM chart," International Journal of Structural Stability and Dynamics, vol. 16, pp. 1-21, 2016.

[24] S. M. O’Connor, Y. L. Zhang, J. P. Lynch, M. M. Ettouney, and P. O. Jansson, "Long-term performance assessment of the Telegraph Road Bridge using a permanent wireless monitoring system and automated statistical process control analytics," Structure and Infrastructure Engineering, vol. 13, no. 5, pp. 604-624, 2017.

[25] K. M. Nassar, W. M. Nassar, and M. Y. Hegab, "Evaluating cost overruns of asphalt paving project using statistical process control methods," Journal of Construction Engineering and Management, vol. 131, no. 11, pp. 1173-1178, 2005.

[26] D. Sarkar and G. Dutta, "Design and application of risk adjusted cumulative sum for strength monitoring of ready mixed concrete," Journal of Construction Engineering and Management, vol. 136, no. 6, pp. 623-631, 2010.

[27] National Railway Administration of People's Republic, China, Code for Design of High Speed Railway, Standard of the People's Republic of China: TB10621-2014, National Railway Administration of People's Republic, Beijing, China, 2015, in Chinese.

[28] Municipal Commission of Housing and Urban-Rural Development, Beijing, Technical Code for Monitoring Measurement of Subway Engineering, Standard of Beijing: DB11/4902007, Municipal Commission of Housing and Urban-Rural Development, Beijing, China, 2007, in Chinese. 